\title{
Lmod2 piggyBac mutant mice exhibit dilated cardiomyopathy
}

\author{
Shuang Li ${ }^{1}$, Kaiqi Mo ${ }^{1}$, Hong Tian², Chen Chu², Shuna Sun ${ }^{2}$, Lei Tian ${ }^{1,3}$, Sheng Ding ${ }^{1,3}$, Tong-ruei Li ${ }^{1}$, \\ Xiaohui Wu ${ }^{1}$, Fang Liu' ${ }^{2}$, Zhen Zhang ${ }^{4}$, Tian $X^{1,3^{*}}$ and Ling V. Sun ${ }^{1 *}$
}

\begin{abstract}
Background: Leiomodin proteins, Lmod1, Lmod2 and Lmod3, are key regulators of the thin filament length in muscles. While $L \bmod 1$ is specifically expressed in smooth muscles, both $L$ mod 2 and $L \bmod 3$ are expressed in striated muscles including both cardiac and skeletal muscles. We and others have previously shown that Lmod3 mainly function in skeletal muscles and the mutant mice display disorganized sarcomere. Lmod2 protein has been found to act as an actin filament nucleator in both cell-free assays and in cultured rat and chicken cardiomyocytes.

Results: To better understand the function of $L$ mod 2 in vivo, we have identified and characterized a piggyBac (PB) insertional mouse mutant. Our analysis revealed that the $P B$ transposon inserts in the first exon of the Lmod2 gene and severely disrupts its expression. We found that $\angle \bmod 2^{P B / P B}$ mice exhibit typical dilated cardiomyopathy (DCM) with ventricular arrhythmias and postnatal lethality. Electron microscope reveals that the $L \bmod 2^{P B / P B}$ hearts carry disordered sarcomere, disarrayed thin filaments, and distorted intercalated discs (ICDs). Those ICDs display not only decreased convolutions, but also reduced electron-dense staining, indicating less ICDs component proteins in $L$ mod2 ${ }^{P B / P B}$ hearts. Consistent with the phenotype, the expression of the ICD component genes, $\beta$-catenin and Connexin43, are down-regulated.
\end{abstract}

Conclusions: Taken together, our data reveal that $L \bmod 2$ is required in heart thin filaments for integrity of sarcomere and ICD and deficient mice exhibit DCM with ventricular arrhythmias and postnatal lethality. The $L$ mod $2^{P B / P B}$ mutant offers a valuable resource for interrogation of pathogenesis and development of therapeutics for DCM.

Keywords: Dilated cardiomyopathy, Leiomodin2 mutant, Sarcomere, Intercalated discs

\section{Background}

The Leiomodin proteins, Lmod1, Lmod2 and Lmod3, are a subgroup of the Tropomodulin (Tmod) protein family and are regulators of the thin filament length in muscles [1-3]. While Lmod1 is specifically expressed in smooth muscles, both $\operatorname{Lmod} 2$ and $\operatorname{Lmod} 3$ are expressed in striated muscles including both cardiac and skeletal muscles [4-6]. We and others have previously shown that Lmod3 mainly functions in skeletal muscles [6-8] and

\footnotetext{
*Correspondence: tian.xu@yale.edu; lingsun@fudan.edu.cn

${ }^{1}$ State Key Laboratory of Genetic Engineering and National Center for International Research of Development and Disease, Fudan-Yale Center for Biomedical Research, Innovation Center for International Cooperation of Genetics and Development, Institute of Developmental Biology and Molecular Medicine, School of Life Sciences, Children's Hospital of Fudan University, Fudan University, Shanghai, China Full list of author information is available at the end of the article
}

Lmod3 mutants exhibit muscle atrophy in fast fibers [6]. The mutant mice display disorganized sarcomere and the presence of nemaline bodies in skeletal muscles, a hallmark of the disease nemaline myopathy (NM), consistent with the finding that $L M O D 3$ is mutated in the NM patients [7].

Lmod2 protein has been found to act as an actin filament nucleator in both cell-free assays and in cultured rat and chicken cardiomyocytes [2,5]. Overexpression of $\operatorname{Lmod} 2$ results in the elongated thin filaments and knockdown exhibited disrupted sarcomere assembly in cultured cardiomyocytes [2,5]. Furthermore, it has been shown that Lmod2 is an antagonist of Tmod1 in cardiomyocytes [2,5]. Knockout mice of Tmod1 are embryonic lethal due to cardiac defects, and overexpression of Tmod1 in the heart causes myofibril disorganization 
and dilated cardiomyopathy (DCM) [9-13]. However, the physiological function of $\operatorname{Lmod} 2$ remains unknown. We hypothesized that the phenotype of loss of Lmod2 in mice might mimic that of the overexpression of its antagonist Tmod1, and the mutant mice are high likely to carry DCM.

Dilated cardiomyopathy is a common form of cardiomyopathies and the third most common inheritable heart disease [14]. DCM is diagnosed as dilated left ventricular accompanied by systolic dysfunction, less than $50 \%$ ejection fraction (EF) [15]. These symptoms may be accompanied by other complications, including arrhythmias, coagulation, and congestive heart failure (CHF), which often lead to lethality $[16,17]$. It has been estimated that DCM causes at least half of heart failures and less than $50 \%$ of the DCM patients survive beyond year 5 after the diagnosis $[16,18,19]$.

To better understand the function of $\operatorname{Lmod} 2$ in vivo, we have identified a piggyBac $(P B)$ insertional mutant that disrupts Lmod2 expression and carried out phenotypic characterization of this mutant. We show here that Lmod2 is crucial for postnatal survival and essential for cardiac function. Lmod2 deficient mice display DCM with disrupted sarcomeres and intercalated discs (ICDs) including the expression of ICD genes, which offer a new mouse model for this deadly disease.

\section{Results}

\section{Generation of $L$ mod2-deficient mice}

Our group has shown that the $P B$ transposon is highly active in mice and human cells and could be used to rapidly generate a large collection of insertional mouse mutants in a cost-effective manner [20]. One of the $P B$ mutants that we generated has an insertion in the $\operatorname{Lmod} 2$ gene $\left(\operatorname{Lmod} 2^{P B /+}\right.$ in $\mathrm{FVB} / \mathrm{N}$ background) [21]. This $P B$ transposon is inserted in the non-coding region of the first exon of the $\operatorname{Lmod} 2$ transcriptional unit (Fig. 1a) and significantly down regulated the expression of the gene as revealed by quantitative RT-PCR (less than 5 and $10 \%$ in homozygous mutant males and females in comparison to wild-type control Fig. 1b).

Tmod1 is an antagonist of Lmod2 at the pointed end of the thin filaments in cardiac muscle [5]. It has been suggested that the expression of Tmod1 could be affected by $\operatorname{Lmod} 2$ [5]. We therefore analyzed the transcriptional level of Tmod1 by quantitative PCR and found that the mRNA level of Tmod 1 remains the same in 25 days old $L m o d 2^{P B / P B}$ hearts compared to controls (Fig. 2a).

Lmod3, another member of the Leiomodin family, also expresses in heart together with $L$ mod2. It might be up regulated to functionally compensate the down-regulation of $L \bmod 2$. However, Western analysis revealed that the Lmod3 protein level in the hearts of $\operatorname{Lmod} 2^{P B / P B}$ is

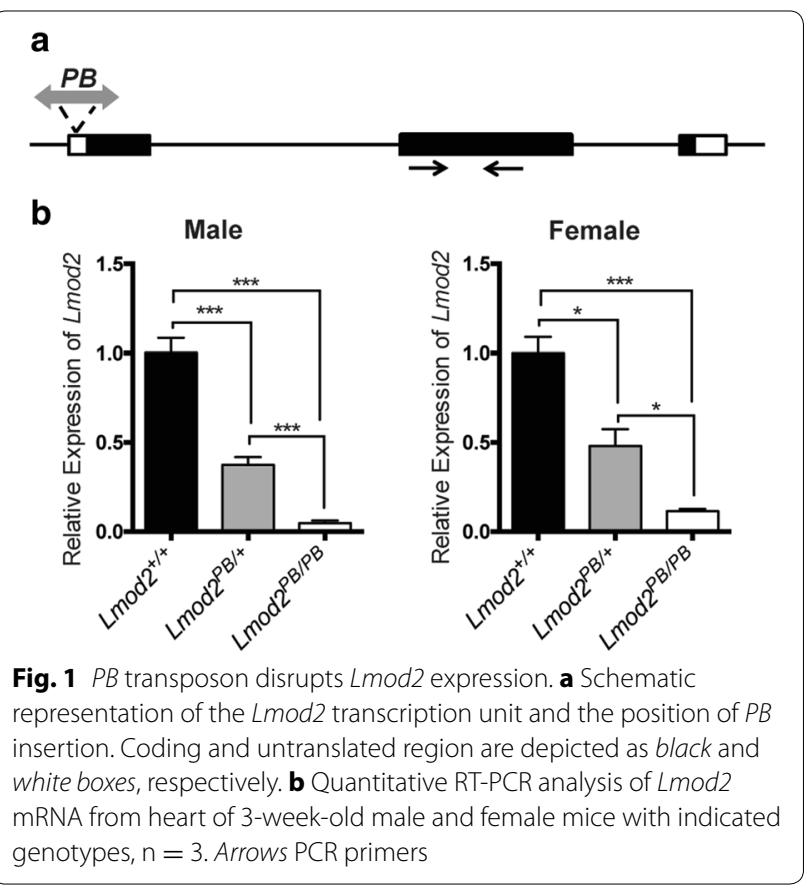

unchanged compared to its controls (Fig. 2b). Together, these data indicate that the phenotypes observed below are likely caused by reduction of $L$ mod 2 gene activity alone and not a compound effect disrupting other Tmod family members.

\section{$L \bmod 2^{P B / P B}$ mice exhibit postnatal lethality}

$L \bmod 2^{P B / P B}$ mice are born with the expected ratio as well as their $\operatorname{Lmod} 2^{P B /+}$ and wild-type littermates. This indicates that Lmod2 is not essential for mouse embryonic development.

While $\operatorname{Lmod} 2^{P B / P B}$ mice are born alive with normal appearance and body weight, the mutant animals exhibit postnatal death around 3rd week of age and are all dead by 9 th week (Fig. 3a). Furthermore, male mutant animals are also underweight after three weeks (Fig. 3b). Heterozygous $L \bmod 2^{P B /+}$ animals have normal life spans and display no discernable phenotype including fertility. This result indicates that $L m o d 2$ is crucial for postnatal survival.

\section{$L \bmod 2^{P B / P B}$ hearts display dilated cardiomyopathy defects} The $L \bmod 22^{P B / P B}$ mice have no overt signs of distress until 1 to 2 days before death. These signs include curling up, less movement, and dyspnea. Given that Lmod2 is expressed in heart [4], these phenotypes suggest that the mutant animals may suffer from cardiac dysfunction.

We therefore conducted histological and physiological analyses of the $\operatorname{Lmod} 2^{P B / P B}$ mutant hearts from 25 days old mice before the animals display any signs of distress. 

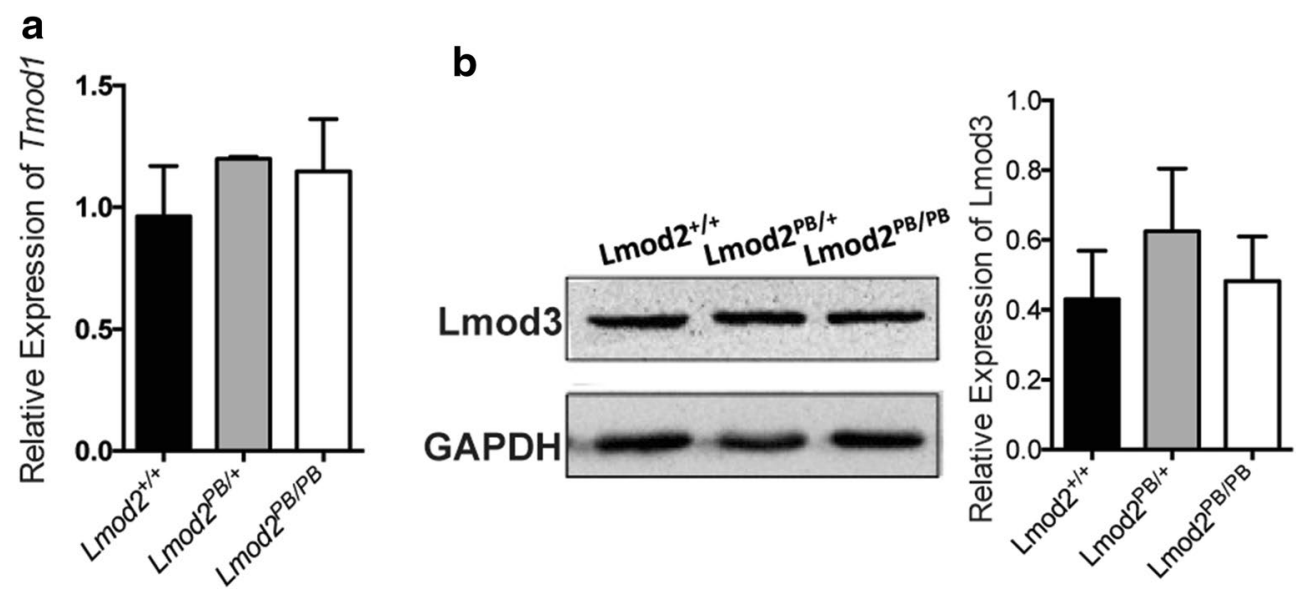

Fig. 2 Tmod1 and Lmod3 Expression in Lmod2 mutant mice. a mRNA level of Tmod 1 is not changed in Lmod2 ${ }^{P B / P B}$ hearts compared with wild-type control. $\mathbf{b} L \bmod 3$ protein level is also not changed in $L \bmod 2^{P B / P B}$ mice as shown here in western blotting and statistics

a

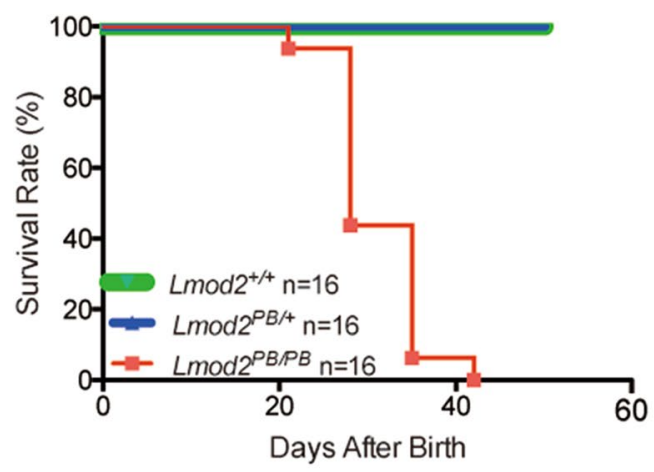

b

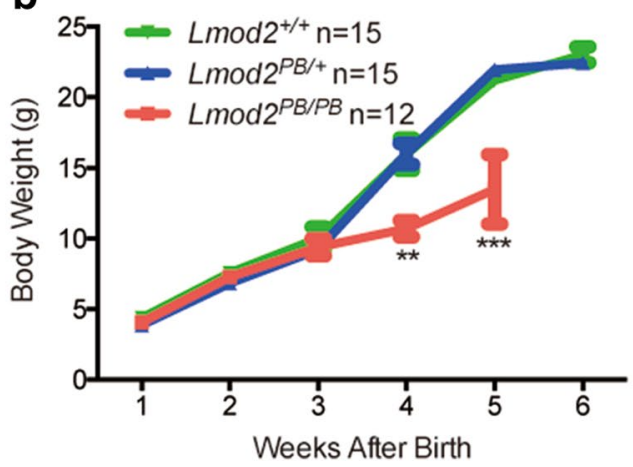

\section{Female}

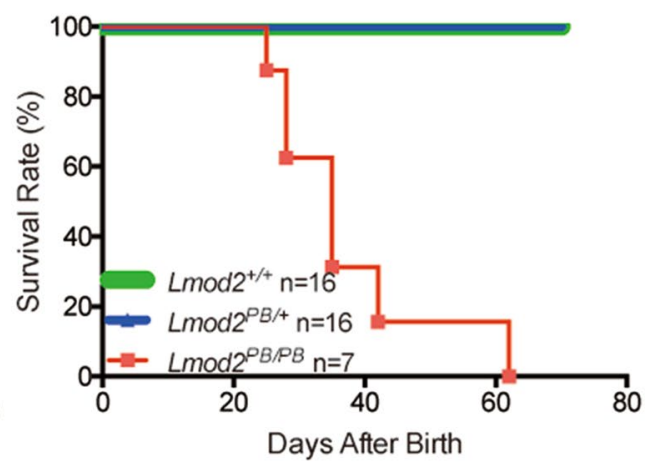

Female

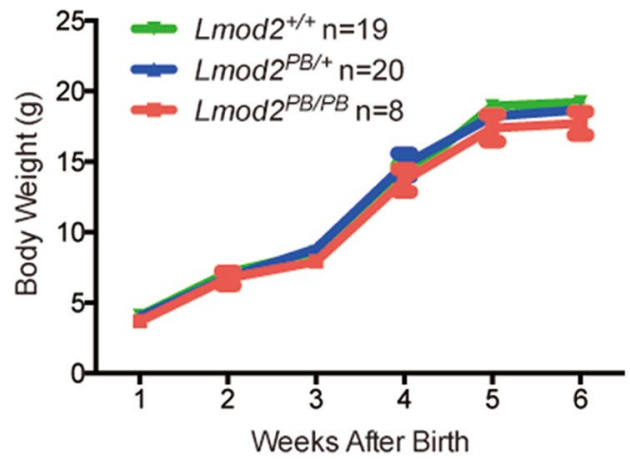

Fig. $3 \mathrm{Lmod} 2^{\mathrm{PB} / \mathrm{PB}}$ mice exhibit postnatal lethality and underweight in surviving males. Survival $\mathbf{a}$ and growth $\mathbf{b}$ curves of male and female Lmo$\mathrm{d} 2^{\mathrm{PB} / \mathrm{PB}}$ mice compared with $\mathrm{Lmod} 2^{\mathrm{PB} /+}$ and $\mathrm{Lmod} 2^{+/+}$mice

Interestingly, all the analyzed $\operatorname{Lmod} 2^{P B / P B}$ mutants display enlarged ventricular lumens and thin ventricular walls, phenocopying the symptoms in human DCM patients $(n=17$, Fig. 4a). The histopathological defects were also confirmed by echocardiography analysis. The mutant hearts had dilated ventricular lumens (Fig. 4b) and thinner heart walls during both systolic and diastolic periods (Fig. 4c). Consistent with these, morphometric 
a

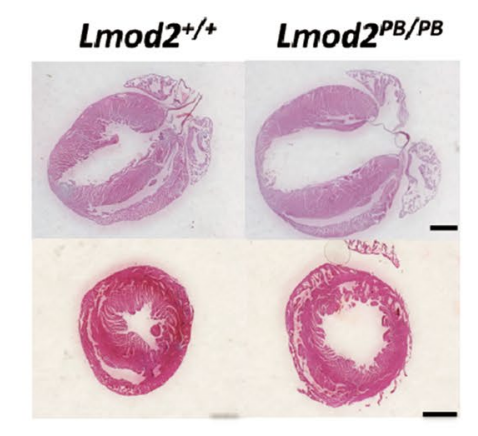

C
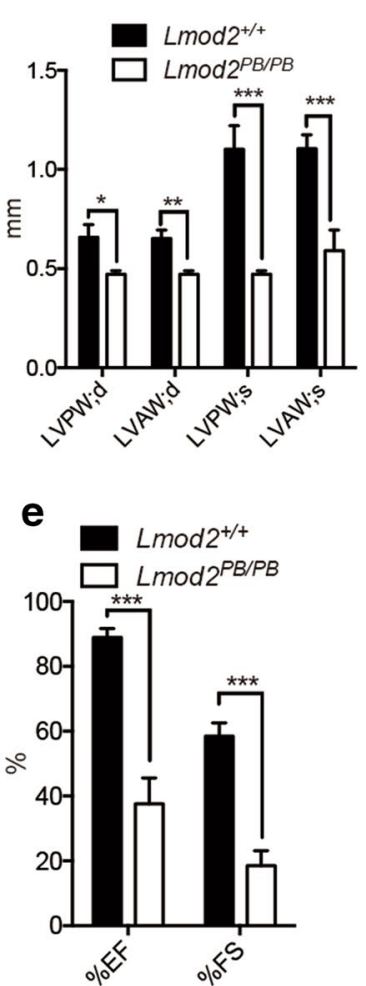

g

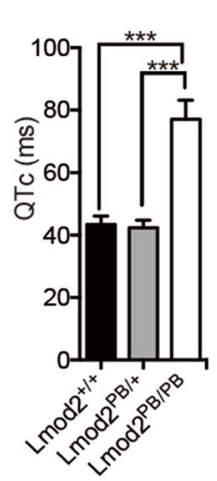

d

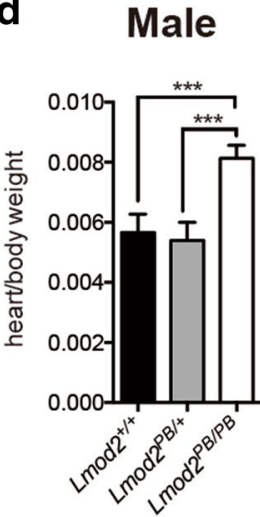

f ANF
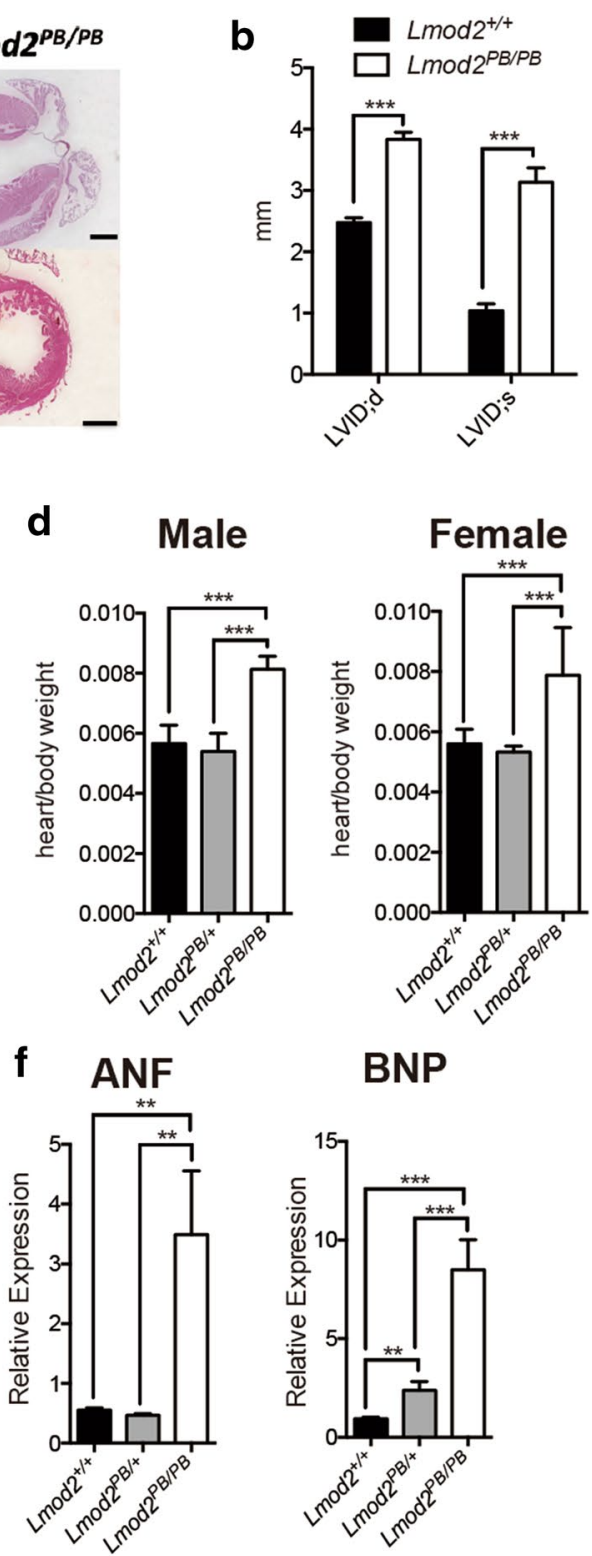

BNP
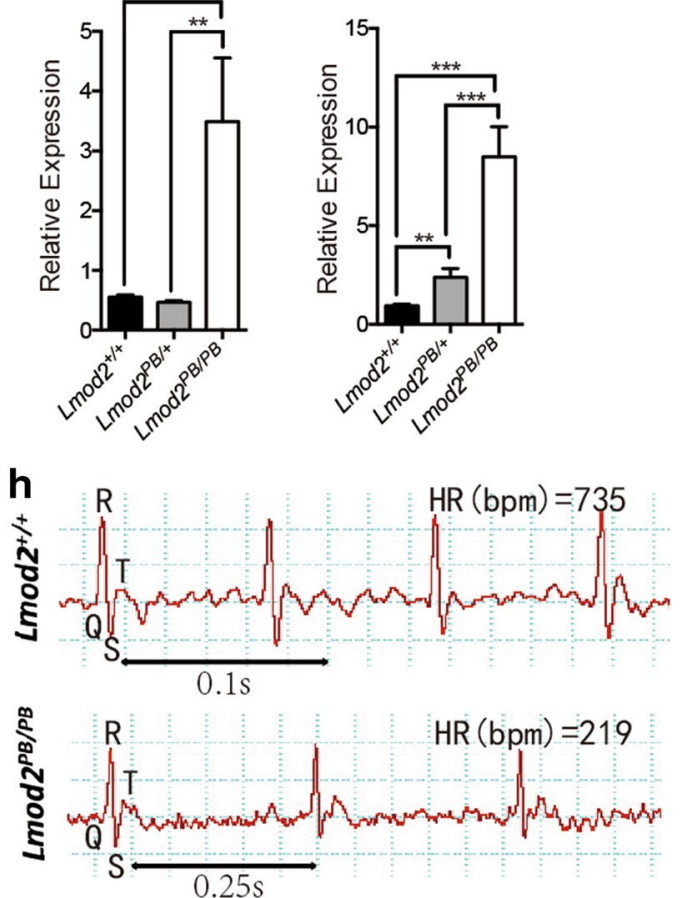
(See figure on previous page.)

Fig. $4 \mathrm{Lmod} 2^{\mathrm{PB} / \mathrm{PB}}$ hearts display dilated cardiomyopathy defects. 25-day old Lmod2 ${ }^{\mathrm{PB} / \mathrm{PB}}$ mice were examined for cardiac morphology and functions. a Longitudinal (upper) and transverse (lower) H\&E stain sections of paraffin-embedded hearts (Scale bar $1 \mathrm{~mm}$ ). b, c, e Echocardiography analysis of $L \bmod 2^{P B / P B}$ hearts in comparison to wild-type control $n=5$. b Higher $L V$ end diastolic and systolic diameter. LVID left ventricular diameter. c Thinner LV anterior and posterior wall. LVPW left ventricular posterior wall; LVAW left ventricular anterior wall. d Morphometric ratios (heart/body weight) of both male and female $L \bmod 2^{\mathrm{PB} / \mathrm{PB}}$ mice are significantly increased. e Reduced ejection fraction and fractional shortening values. $\mathbf{f}$ Quantitative RT-PCR analysis of atrial natriuretic factor (ANF) and brain natriuretic peptide (BNP) revealed increased expression of the heart hypertrophy and heart failure biomarkers $n=3$. LV left ventricle; d diastolic; s: systolic. $\mathbf{g}, \mathbf{h}$ Electronic Cardiogram revealed lengthening QTc value of $\mathrm{Lmod} 2^{\mathrm{PB} / \mathrm{PB}}$ mice in comparison to controls

ratios (heart weight/body weight) were increased in these animals as well (Fig. 4d).

Echocardiography analysis also revealed that the mutant hearts displayed lower ejection fraction (EF) and fraction shortening (FS) values (Fig. 4e), characteristic DCM deficit. Furthermore, electrocardiography (ECG) analysis revealed lengthened corrected QT interval (QTc) in $\operatorname{Lmod} 2^{P B / P B}$ mice in comparison to controls (Fig. $4 \mathrm{~g}$, h). The lengthened QTc value means delayed electrical repolarization of the ventricles, indicating ventricular arrhythmia [22], complications that many DCM patients also develop.

The expression of atrial natriuretic factor (ANF) and brain natriuretic peptide (BNP) were examined in mutant animals before signs of heart failure [23]. We discovered that the $L \bmod 2^{P B / P B}$ mutant mice already exhibited a significant increase in gene expression for the heart hypertrophy and heart failure biomarkers (Fig. 4f). Finally, Masson's Trichrome staining revealed that there was no observable increase in fibrosis in these animals (data not shown).

\section{Lmod2-deficiency leads to sarcomere and ICD disorganization}

We further characterized cardiac muscles of $\operatorname{Lmod} 2^{P B /}$ $P B$ mice (25 days old) by paraffin section and transmission electron microscope (EM). We noticed that the area between the muscle fibers is larger in $\operatorname{Lmod} 2^{P B / P B}$ cardiac muscles than the wild-type control (Fig. 5a, b, i). EM analysis revealed altered sarcomeres with irregular Z-discs and unidentifiable $M$-lines in $\operatorname{Lmod} 2^{P B / P B}$ cardiac fibers (Fig. 5c-f). For those fibers with recognizable Z-discs, measuring the length of the sarcomeres revealed shorter sarcomeres than wild-type control (Fig. 5j). Moreover, the filaments in the $\operatorname{Lmod} 2^{P B / P B}$ cardiac fibers are also disarrayed in comparison to wild-type control (Fig. 5e, f). Finally, the ICDs in $\operatorname{Lmod} 2^{P B / P B}$ cardiac fibers are less convoluted and have reduced electron dense (Fig. $5 \mathrm{~g}, \mathrm{~h}$ ). The ICD morphological changes suggest that the mutant fibers might have less ICD proteins. Quantitative RTPCR (QPCR) indeed identified reduced expression of two of major ICD genes, $\beta$-catenin and Connexin43 (Cx43), components of fascia adherens and gap junctions, respectively (Fig. 5k). Together, these data indicate that Lmod2 deficient cardiac fibers have disrupted sarcomeres and ICDs including the expression of ICD genes.

\section{Discussion}

Using $P B$ insertional mutants, we have studied two members of the Lmod family, Lmod2 and Lmod3, which express in the cardiac and skeletal muscles. We previously reported that $L$ mod 3 deficiency lead to severe skeletal muscle weakness with atrophy specific to fast fibers [6]. EM analysis revealed disorganized sarcomeres in skeletal muscles of Lmod3 mutant mice.

Here we report the characterization of Lmod2-deficient mice caused by $P B$ insertion in the first exon. Unlike Lmod3-deficient mice that are born small with skeletal muscle atrophy [6], Lmod2-deficient animals are born with normal appearance and body weight. Only male Lmod2-deficient mice exhibit underweight in the 4th week. On the other hand, Lmod2-deficient mice exhibit postnatal lethality and all mutant animals die from 3 to 9 weeks after birth. This postnatal lethality together with previous report of $\operatorname{Lmod} 2$ in cultured cardiomyocytes [2, 5] suggests a role of the gene in cardiac function.

We have therefore carried out a pathological analysis of the Lmod2 mutant heart. Our study shows that the Lmod 2 mutant hearts have enlarged ventricular with systolic dysfunction reflected with EF value less than $50 \%$, features that are characteristic to DCM patients. Investigation with transmission electron microscopy reveals that the $\operatorname{Lmod} 2^{P B / P B}$ cardiac muscles exhibit disordered sarcomeres and ICDs. The morphologies of Z-discs, M-lines, and thin filaments in sarcomeres are all affected.

Intercalated disc is composed of highly organized fascia adherens, gap junctions and desmosomes, and glues cardiomyocytes together. Disruption of ICD would also lead to cardiomyopathy [24]. Recently, it has been shown that mutation in non-ICD component protein could also result in ICD structure abnormality and cardiomyopathy [25]. In the previous reported case, an increase in convolutions of ICD was reported in the cardiomyopathy patient [25]. Here we show that $\operatorname{Lmod} 2^{P B / P B}$ cardiomyocytes have a decrease in ICD convolution and cardiomyopathy. Disruption of ICD is also confirmed by reduction in electron density and expression of two of major ICD 

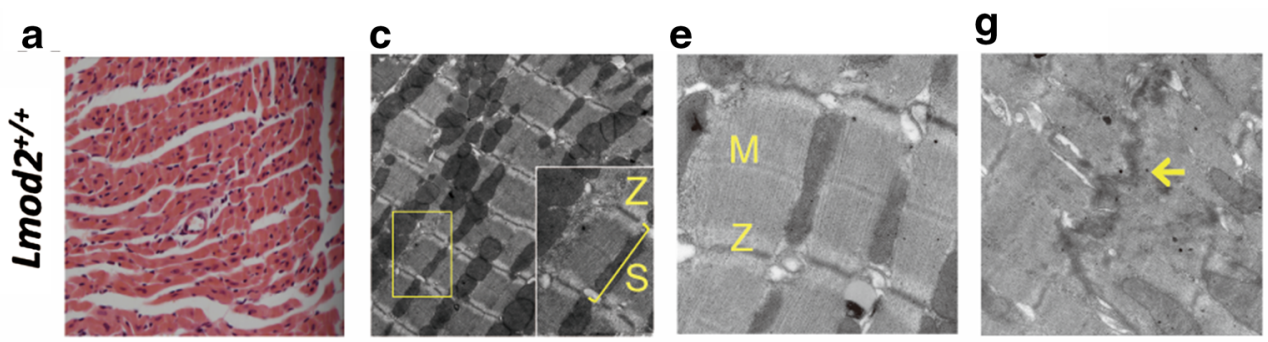

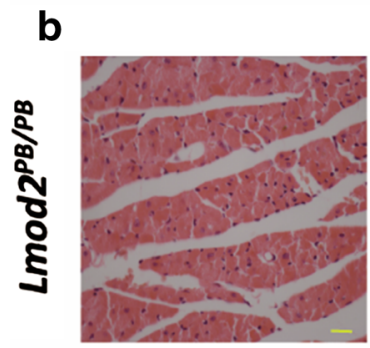

d

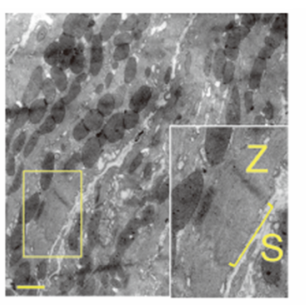

i

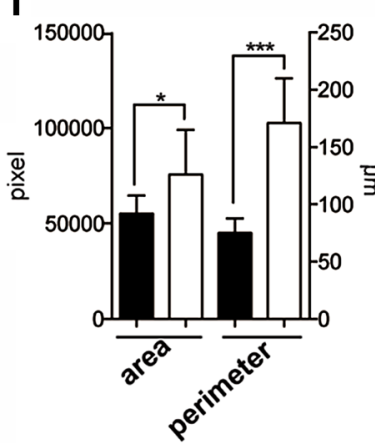

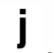

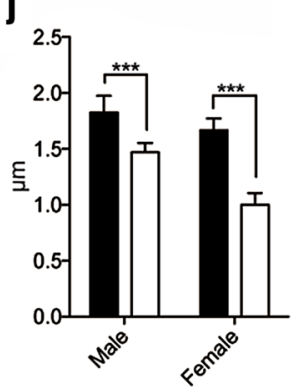

f

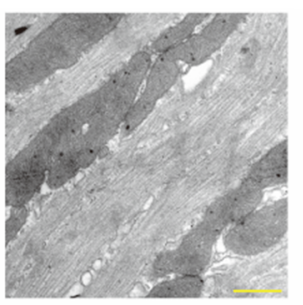

h

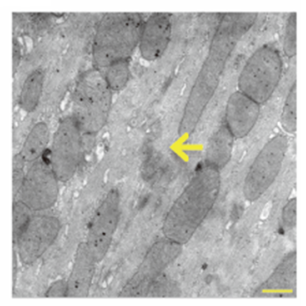

k

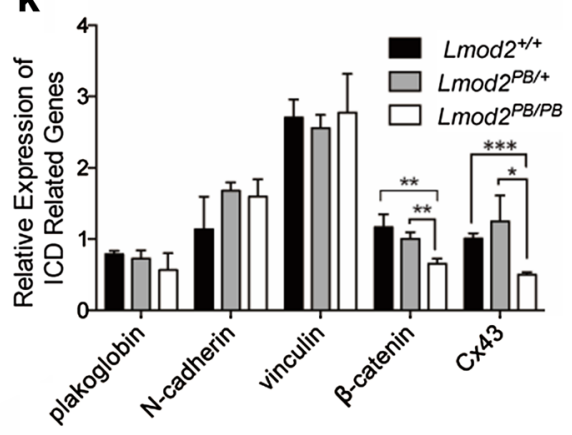

Fig. 5 ICD and sarcomere defects of $L \bmod 2^{P B / P B}$ heart fibers and reduced expression of ICDs proteins. $\mathbf{a}$, $\mathbf{b}$ Longitudinal sections of $25 \mathrm{~d}$ paraffinembedded hearts stained with H\&E. c-h Representative electron micrographs of cardiac LV tissue from 25 days old Lmod2 $2^{+/+}(\mathbf{c}, \mathbf{e}, \mathbf{g})$ and Lmod2 $2^{\mathrm{PB} /}$

${ }^{\mathrm{PB}}(\mathbf{e}, \mathbf{f}, \mathbf{h})$ mice. Sarcomeres $(\mathrm{S})$ are shortened and disorganized in $\mathrm{Lmod} 2^{\mathrm{PB} / \mathrm{PB}}$ myocardium $(\mathbf{c}, \mathbf{d})$. Z-discs (Z) and M-lines (M) are disorganized and unrecognizable, respectively, in $\mathrm{Lmod} 2^{\mathrm{PB} / \mathrm{PB}}$ myocardium $(\mathbf{e}, \mathbf{f})$. Reduced convolution and electron dense of ICD (arrow) in $\mathrm{Lmod} 2^{\mathrm{PB} / \mathrm{PB}}$ myocardium $(\mathbf{g}, \mathbf{h})$. i Area and perimeter of the area between the muscle fibers are increased in $L \bmod 2{ }^{P B / P B}$ hearts compared with wild-type control $n=8 . \mathbf{j}$ Statistics of sarcomere length in $L \bmod 2^{P B / P B}$ myocardium $n=20$. $\mathbf{k}$ Quantitative RT-PCR of major intercalated disCS (ICD) genes $n=3$. Scale bars $200 \mu \mathrm{m}$ in $\mathbf{b}, 1 \mu \mathrm{m}$ in $\mathbf{d}, 500 \mu \mathrm{m}$ in $\mathbf{f}, \mathbf{h}$

genes, $\beta$-catenin and Connexin43 (Cx43), components of fascia adherens and gap junctions. Therefore, $L \bmod 2^{P B /}$ ${ }^{P B}$ mouse model represents a new ICD phenotype related to DCM. During preparation of our manuscript, we noticed that a report of $\operatorname{Lmod} 2$ knockout mouse characterization [26]. While DCM was observed in both models, there were differences in ultrastructure of cardiac muscles. In contrast to $\operatorname{Lmod} 2^{P B / P B}$ phenotypes, $\operatorname{Lmod} 2$ knockout model reported widen Z-discs and increased convolutions of ICDs [26]. The difference could be due to the C57BL/6J background for the Lmod2 knockout and $\mathrm{FVB} / \mathrm{N}$ for $\operatorname{Lmod} 2^{P B / P B}$.

The morphological defects in cardiac muscles proceed the symptom of heart failure in animals. Similarly, the expressions of the heart hypertrophy and heart failure biomarkers, atrial natriuretic factor (ANF) and brain natriuretic peptide (BNP), are elevated before the detection of heart failure. Together, these data show that Lmod2 deficiency leads to structure abnormality of cardiac muscles, which results in DCM, and that $\operatorname{Lmod} 2^{P B / P B}$ mice offer a new model for studying DCM mechanisms and developing therapeutics.

\section{Conclusion}

Taken together, our data reveal that Lmod2 is required in heart thin filaments for integrity of sarcomere and ICD and deficient mice exhibit DCM with ventricular arrhythmias and postnatal lethality. The $\operatorname{Lmod} 2^{\mathrm{PB} /}$ ${ }^{\mathrm{PB}}$ mutant offers a valuable resource for interrogation of pathogenesis and development of therapeutics for DCM. 


\section{Methods}

\section{Mouse strains}

The founder $\operatorname{Lmod} 2^{P B /+}$ mouse was produced by a largescale genome-wide insertional mutagenesis with the $P B$ transposon in the $\mathrm{FVB} / \mathrm{N}$ mice $[20,27]$.

\section{Genotyping}

Genomic DNA was isolated by a $56{ }^{\circ} \mathrm{C}$ overnight digestion of mouse toes in $200 \mu \mathrm{L}$ lysis buffer $(100 \mathrm{mM}$ $\mathrm{NaCl}, 10 \mathrm{mM}$ Tris pH 8.0, $25 \mathrm{mM}$ EDTA, and $0.5 \%$ SDS) plus fresh $0.1 \mathrm{mg} / \mathrm{ml}$ proteinase K. PCR was performed with primers within exon 1 of $\operatorname{Lmod} 2$ (forward: 5'-AGCTGTCGGCTTTCAATTTTTTTCC-3'; reverse: 5'-TGTCTTCCAGCTCCСТCTCAAG-3', 247 bp product) and primers within the $\mathrm{PB}$ transposon (forward: 5'-CTGAGATGTCCTAAATGCACAGCG-3' and reverse: 5'-TGTCTTCCAGCTCCCTCTCAAG-3', 819 bp product). PCR conditions used were as the following: an initial denaturation step at $93{ }^{\circ} \mathrm{C}$ for $3 \mathrm{~min}$, then followed by a 40 cycle of $93^{\circ} \mathrm{C}$ for $30 \mathrm{~s} / 57^{\circ} \mathrm{C}$ for $30 \mathrm{~s} / 65^{\circ} \mathrm{C}$ for $2 \mathrm{~min}$, and one more elongation at $65^{\circ} \mathrm{C}$ for $10 \mathrm{~min}$ as the final step.

\section{Reverse transcription and quantitative RT-PCR}

Total RNA was isolated from 3-week-old mouse heart with Trizol (Invitrogen). The cDNA was synthesized then using the PrimeScript ${ }^{\mathrm{TM}}$ RT reagent Kit (Takara). Quantitative RT-PCR was performed with AceQ qPCR SYBR Green Master Mix (Vazyme) according to the manufacturer's instruction. All quantitative RT-PCR primers are listed in Table 1.

\section{Table 1 Quantitative RT-PCR primers}

\begin{tabular}{|c|c|c|}
\hline Gene & Forward $\left(5^{\prime} \rightarrow 3^{\prime}\right)$ & Reverse $\left(5^{\prime} \rightarrow 3^{\prime}\right)$ \\
\hline$L \bmod 2$ & $\begin{array}{l}\text { ACCTTATCCCGATTTGCTGA } \\
\text { AG }\end{array}$ & ACCTTGAGCATGTCTGCAATG \\
\hline GAPDH & $\begin{array}{l}\text { TGTTCCTACCCCCAATGTGT } \\
\text { CC }\end{array}$ & $\begin{array}{l}\text { GGAGTTGCTGTTGAAGTCGC } \\
\text { AG }\end{array}$ \\
\hline Tmod1 & $\begin{array}{l}\text { TGAGCTAGATGAACTAGAC } \\
\text { CCTG }\end{array}$ & $\begin{array}{l}\text { CGGTCCTTAAATTCCTTCGC } \\
\text { TTG }\end{array}$ \\
\hline ANF & $\begin{array}{l}\text { CATCACCCTGGGCTTCTT } \\
\text { СCT }\end{array}$ & CATCACCCTGGGCTTCTTCCT \\
\hline BNP & $\begin{array}{l}\text { GCGGCATGGATCTCCTGAA } \\
\text { GG }\end{array}$ & $\begin{array}{l}\text { GCGGCATGGATCTCCTGAA } \\
\text { GG }\end{array}$ \\
\hline Plakoglobin & $\begin{array}{l}\text { TGGCAACAGACATACACCT } \\
\text { ACG }\end{array}$ & $\begin{array}{l}\text { GGTGGTAGTCTTCTTGAGTG } \\
\text { TG }\end{array}$ \\
\hline $\mathrm{N}$-cadherin & $\begin{array}{l}\text { AGCGCAGTCTTACCGAA } \\
\text { GG }\end{array}$ & $\begin{array}{l}\text { TCGCTGCTTTCATACTGAA } \\
\text { CTTT }\end{array}$ \\
\hline Vinculin & $\begin{array}{l}\text { GAGGCTGAACTGCTTCA } \\
\text { ATCA }\end{array}$ & CCAGATTTGACGAGGTGCCTA \\
\hline$\beta$-catenin & $\begin{array}{l}\text { ATGGAGCCGGACAGAAA } \\
\text { AGC }\end{array}$ & CTTGCCACTCAGGGAAGGA \\
\hline Cx43 & $\begin{array}{l}\text { ACAGCGGTTGAGTCAGC } \\
\text { TTG }\end{array}$ & $\begin{array}{l}\text { GAGAGATGGGGAAGGA } \\
\text { CTTGT }\end{array}$ \\
\hline
\end{tabular}

\section{Western blotting}

Hearts were dissected and lysed in RIPA buffer with Complete Protease inhibitors (Roche) and PMSF (Phenylmercury acetate) (Sigma) on ice. The BCA Assay (Themo) was applied to quantify total proteins extracted. The western blotting procedure was carried out according to standard protocol with a brief introduction here. Protein bands were separated by SDS/ PAGE and transferred to nitrocellulose membranes (Immobilon-P). The transferred membrane was blotted first $5 \%$ skim milk for $1 \mathrm{~h}$. Blots were then incubated with a primary antibody and a secondary antibody consecutively to detect protein of interest. Primary antibodies used are the following: Lmod3 (1:1000; HPA036034, Sigma), GAPDH (1:3000; AC001, ABclonal). Secondary antibody used is the Anti-rabbit IgG antibody conjugated to PerCP-Cy5.5 (1:3000; sc-45101, Santa Cruz). Signal was finally visualized by enhanced chemiluminescence (34,080, Themo).

\section{Echocardiography and ECG}

Mice were anesthetized by inhalation of 1-2 \% isoflurane delivered in a gas mixture with oxygen, medicalgrade compressed air, and nitrogen. The anesthetized mice went through echocardiography with the Vevo 770 microultrasound system (VisualSonics Inc. Toronto, Canada). Both parasternal long-axis and short-axis views of the left ventricles were analyzed with a 707B transducer according to the manufacturer's instruction. Data were recorded in $M$ mode.

Conscious and unrestrained mice were used for ECG analysis with the ECGenie electrocardiography system (Mouse Specifics, Inc., Boston, MA) according to the manufacturer's instruction. Before experimental tests, mice should be trained for 3-5 days to behave normally in this machine. Only data from continuous recordings of 20-30 ECG signals were included in the final analyses. A physiologic waveform analysis platform "eMOUSE" (Mouse Specifics, Inc.) was applied for data analysis.

\section{Transmission electron microscopy}

Samples for transmission electron microscopy were prepared using the standard procedure: hearts were excised, washed in PBS, fixed in $2.5 \%$ glutaraldehyde in $0.1 \mathrm{M}$ cacodylate buffer for more than $2 \mathrm{~h}$, washed in $0.1 \mathrm{M}$ cacodylate buffer for $3 \times 15 \mathrm{~min}$, post-fixed with $1 \%$ potassium ferrocyanide reduced $\mathrm{OsO}_{4}$ on ice for 2-3 h, dehydrated through graded ethanol and acetone, and finally embedded in EMbed 812 resin. Ultrathin sections $(60 \mathrm{~nm})$ were analyzed on a Technai G2 Spirit BioTWIN electron microscope, and images were collected with a $4 \times 4$ digital camera (Optronics). Length of sarcomere was measured using ImageJ. 


\section{Histology}

Hearts were excised, washed in PBS, fixed in $4 \%$ paraformaldehyde solution (Sangon Biotech) overnight, dehydrated, and embedded in paraffin. Longitudinal or transverse sections $(10 \mu \mathrm{m})$ were stained with a Masson Trichrome Stain Kit (Maixin Biotech) or according to the classical hematoxylin and eosin (H\&E) staining protocol (Sigma), and finally mounted with DPX Mountant (Sigma). Light microscopy images were captured using a Nikon Eclipse microscope with a Nikon DS-Ri1 camera and/or a Zeiss Axio Zoom V16 stereomicroscope with an AxioCam MRc camera.

\section{Statistics}

Data were presented as mean \pm SED in figures. Twotailed unpaired Student's t-test was used unless otherwise stated. The significance is indicated as the label of one or more * with the following categories: $(1) * \mathrm{P}<0.05$; (2) ** $\mathrm{P}<0.01 ; 3){ }^{* * *} \mathrm{P}<0.005$. Prism 6 (GraphPad Software) was used for plotting.

\begin{abstract}
Abbreviations
ANF: atrial natriuretic factor; BNP: brain natriuretic peptide; CHF: congestive heart failure; DCM: dilated cardiomyopathy; ECG: electrocardiography; EF: ejection fraction; EM: electron microscope; FS: fraction shortening; ICD: intercalated discs; Lmod: leiomodin; Lmod1: leiomodin 1; Lmod2: leiomodin2; Lmod3: leiomodin3; LV: left ventricle; LVAW: left ventricular anterior wall; LVID: left ventricular diameter; LVPW: left ventricular posterior wall; PB: piggyBac; QTc: corrected QT interval; Tmod1: tropomodulin1.
\end{abstract}

\section{Authors' contributions}

SL, TX and LVS designed the project; SL, KM, HT, CC, and SS did the experiments and collected data; SL, KM, LT, SD, TL, XW, FL, ZZ, TX and LVS analyzed the data; SL, TX and LVS prepared the manuscript; TX and LVS supervised all aspects of the work. All authors read and approved the final manuscript.

\section{Author details}

${ }^{1}$ State Key Laboratory of Genetic Engineering and National Center for International Research of Development and Disease, Fudan-Yale Center for Biomedical Research, Innovation Center for International Cooperation of Genetics and Development, Institute of Developmental Biology and Molecular Medicine, School of Life Sciences, Children's Hospital of Fudan University, Fudan University, Shanghai, China. ${ }^{2}$ Cardiac Center, Children's Hospital of Fudan University, Shanghai, China. ${ }^{3}$ Howard Hughes Medical Institute, Department of Genetics, Yale University School of Medicine, New Haven, CT, USA. ${ }^{4}$ Shanghai Pediatric Congenital Heart Institute, Institute of Pediatric Translational Medicine, Shanghai Children's Medical Center, Shanghai Jiaotong University, School of Medicine, Shanghai, China.

\section{Acknowledgements}

We thank Ms. Yanfeng Tan and Ms. He Tan in the Institute of Developmental Biology and Molecular Medicine, Fudan University, for technical support, and 973 and 863 working group, Dr. Yuan Zhuang, and other IDM members for scientific discussion.

\section{Competing interests}

The authors declare that they have no competing interests.

\section{Consent for publication}

Not applicable.

\section{Ethics approval and consent to participate}

All animal procedures applied in this article have been approved by the Animal Care and Use Committee of the Institute of Developmental Biology and Molecular Medicine, Fudan University, Shanghai, China.

\section{Funding}

This work was supported by the following grants: Chinese Key Projects for Basic Research (973) Grants 2013CB945301 and 2013CB945304; Chinese Hitech Research and Development Project of China (863) Grants 2012AA022401 and 2014AA021104; National Natural Science Foundation of China grant 81170789; and National Institutes of Health grant U01HG004073. TX is a Howard Hughes Medical Institute Investigator.

Received: 26 January 2016 Accepted: 3 May 2016

Published online: 04 June 2016

\section{References}

1. Conley CA, Fritz-Six KL, Almenar-Queralt A, Fowler VM. Leiomodins: larger members of the tropomodulin (Tmod) gene family. Genomics. 2001;73(2):127-39.

2. Chereau D, Boczkowska M, Skwarek-Maruszewska A, Fujiwara I, Hayes DB, Rebowski G, et al. Leiomodin is an actin filament nucleator in muscle cells. Science. 2008;320(5873):239-43.

3. Nworu CU, Kraft R, Schnurr DC, Gregorio CC, Krieg PA. Leiomodin 3 and tropomodulin 4 have overlapping functions during skeletal myofibrillogenesis. J Cell Sci. 2015;128(2):239-50.

4. Nanda V, Miano JM. Leiomodin 1, a new serum response factor-dependent target gene expressed preferentially in differentiated smooth muscle cells. J Biol Chem. 2012:287(4):2459-67.

5. Tsukada T, Pappas CT, Moroz N, Antin PB, Kostyukova AS, Gregorio CC. Leiomodin-2 is an antagonist of tropomodulin-1 at the pointed end of the thin filaments in cardiac muscle. J Cell Sci. 2010;123(Pt 18):3136-45.

6. Tian L, Ding S, You Y, Li TR, Liu Y, Wu X, et al. Leiomodin-3-deficient mice display nemaline myopathy with fast-myofiber atrophy. Dis Model Mech. 2015:8(6):635-41.

7. Yuen M, Sandaradura SA, Dowling JJ, Kostyukova AS, Moroz N, Quinlan $K G$, et al. Leiomodin-3 dysfunction results in thin filament disorganization and nemaline myopathy. J Clin Invest. 2014;124(11):4693-708.

8. Cenik BK, Garg A, MCAnally JR, Shelton JM, Richardson JA, Bassel-Duby R, et al. Severe myopathy in mice lacking the MEF2/SRF-dependent gene leiomodin-3. J Clin Invest. 2015;125(4):1569-78.

9. Chu X, Chen J, Reedy MC, Vera C, Sung KL, Sung LA. E-Tmod capping of actin filaments at the slow-growing end is required to establish mouse embryonic circulation. Am J Physiol Heart Circ Physiol. 2003;284(5):H1827-38.

10. Fritz-Six KL, Cox PR, Fischer RS, Xu B, Gregorio CC, Zoghbi HY, et al. Aberrant myofibril assembly in tropomodulin1 null mice leads to aborted heart development and embryonic lethality. J Cell Biol. 2003;163(5):1033-44.

11. Sussman MA, Welch S, Cambon N, Klevitsky R, Hewett TE, Price R, et al. Myofibril degeneration caused by tropomodulin overexpression leads to dilated cardiomyopathy in juvenile mice. J Clin Invest. 1998;101(1):51-61.

12. McKeown CR, Nowak RB, Moyer J, Sussman MA, Fowler VM. Tropomodulin1 is required in the heart but not the yolk sac for mouse embryonic development. Circ Res. 2008;103(11):1241-8.

13. Ono Y, Schwach C, Antin PB, Gregorio CC. Disruption in the tropomodulin1 (Tmod1) gene compromises cardiomyocyte development in murine embryonic stem cells by arresting myofibril maturation. Dev Biol. 2005;282(2):336-48.

14. Simpson S, Edwards J, Ferguson-Mignan TF, Cobb M, Mongan NP, Rutland CS. Genetics of human and canine dilated cardiomyopathy. Int J Genomics. 2015;2015:204823.

15. McKenna CJ, Codd MB, McCann HA, Sugrue DD. Idiopathic dilated cardiomyopathy: familial prevalence and HLA distribution. Heart. 1997;77(6):549-52. 
16. Grogan M, Redfield MM, Bailey KR, Reeder GS, Gersh BJ, Edwards WD, et al. Long-term outcome of patients with biopsy-proved myocarditis: comparison with idiopathic dilated cardiomyopathy. J Am Coll Cardiol. 1995;26(1):80-4.

17. National Clinical Guideline Centre. Chronic heart failure: the management of chronic heart failure in adults in primary and secondary care. London: National Clinical Guideline Centre; 2010. Available from: http://guidance. nice.org.uk/CG108/Guidance/pdf/English.

18. Hershberger RE, Morales A, Siegfried JD. Clinical and genetic issues in dilated cardiomyopathy: a review for genetics professionals. Genet Med. 2010:12(11):655-67.

19. Raju H, Alberg C, Sagoo GS, Burton H, Behr ER. Inherited cardiomyopathies. BMJ. 2011;343:d6966.

20. Ding S, Wu X, Li G, Han M, Zhuang Y, Xu T. Efficient transposition of the piggyBac (PB) transposon in mammalian cells and mice. Cell. 2005;122(3):473-83.

21. PiggyBac Mutagenesis Information Center. http://www.idmshanghai.cn/ PBmice/. Accessed 21 Nov 2012
22. Towbin JA, Vatta M. Molecular biology and the prolonged QT syndromes. Am J Med. 2001;110(5):385-98.

23. Wang TJ, Larson MG, Levy D, Benjamin EJ, Leip EP, Omland T, et al. Plasma natriuretic peptide levels and the risk of cardiovascular events and death. N Engl J Med. 2004;350(7):655-63.

24. Ehler E, Horowits R, Zuppinger C, Price RL, Perriard E, Leu M, et al. Alterations at the intercalated disk associated with the absence of muscle LIM protein. J Cell Biol. 2001;153(4):763-72.

25. Purevjav E, Arimura T, Augustin S, Huby AC, Takagi K, Nunoda S, et al. Molecular basis for clinical heterogeneity in inherited cardiomyopathies due to myopalladin mutations. Hum Mol Genet. 2012;21(9):2039-53.

26. Pappas CT, Mayfield RM, Henderson C, Jamilpour N, Cover C, Hernandez $Z$, et al. Knockout of Lmod2 results in shorter thin filaments followed by dilated cardiomyopathy and juvenile lethality. Proc Natl Acad Sci USA 2015;112(44):13573-8.

27. Sun LV, Jin K, Liu Y, Yang W, Xie X, Ye L, et al. PBmice: an integrated database system of piggyBac (PB) insertional mutations and their characterizations in mice. Nucleic Acids Res. 2008:36 (Database issue):D729-34.

\section{Submit your next manuscript to BioMed Central and we will help you at every step:}

- We accept pre-submission inquiries

- Our selector tool helps you to find the most relevant journal

- We provide round the clock customer support

- Convenient online submission

- Thorough peer review

- Inclusion in PubMed and all major indexing services

- Maximum visibility for your research

Submit your manuscript at www.biomedcentral com/submit 